\title{
Caring Behavior of Nurses Increase Level of Client's Satisfaction in Clinical Area
}

\author{
Agussalim*, Muhammad Asikin, M Nasir, I Takko Podding, Alamsyah and Rahman \\ Pare-Pare School of Nursing, Health Polytechnic of Makassar, Jalan Laupe, Kecamatan Soreang, Indonesia
}

*Corresponding author: Agussalim, Pare-Pare School of Nursing, Health Polytechnic of Makassar, Jalan Laupe, Kecamatan Soreang, Kota Parepare, Sulawesi Selatan, Indonesia.

To Cite This Article: Agussalim, Muhammad Asikin, M Nasir, I Takko Podding, Alamsyah, Rahman, Caring Behavior of Nurses Increase Level of Client's Satisfaction in Clinical Area. 2020 - 10(5). AJBSR.MS.ID.001544. DOI: 10.34297/AJBSR.2020.10.001544.

Received: 眥 October 05, 2020; Published: 紫 October 20, 2020

\begin{abstract}
Background: Nurse caring behavior is one aspect that is very related to nursing services, because caring includes human relationships and affects the quality of service and patient satisfaction. Patient satisfaction is the result of an assessment in the form of an emotional response (feeling happy and satisfied) to the patient because of the fulfillment of expectations or desires in using and receiving nurse services. Patient satisfaction is an evaluation or assessment after using a service that the selected service at least meets or exceeds expectations. The research design used is a descriptive correlational quantitative research method using a cross sectional approach; sampling technique is purposive sampling. The numbers of sampling were 41 respondents. Data collection instruments using a questionnaire Chi-Square test with a significance level $\alpha=0$, 05 . Based on the Fisher's Exact Test, p value $=0.018>(\alpha=0.05)$, which means there is a relationship between nurses caring behavior with the level of patient satisfaction in Labuang Baji Makassar Hospital. Thus, it was concluded that there was a relationship between nurses caring behavior with the level of patient satisfaction in Labuang Baji Hospital Makassar. For further researchers were expected to make the basic data to conduct more specific research on the Relationship between Nurse Caring Behavior and Client's Satisfaction Level.
\end{abstract}

\section{Introduction}

The hospital is a medical and basic medical support center, medical support services, care services (outpatient and inpatient), and installation services. The hospital as one of the health facilities is used by the government and the community [1]. Hospitals have a very strategic role in efforts to accelerate the improvement of public health status. The new paradigm of health care requires hospitals to provide quality services according to the needs and wishes of patients while still referring to the professional code of ethics [2].

At the hospital, the resources that contribute the most to supporting patient satisfaction, one of which is the nurse. The nurse gives a big influence to determine the quality of service. Nurses are as the spearhead of service to patients and their families in the hospital, because of the frequency of meetings with the most frequent patients [3].

Nurses are a vital element in a hospital or health service. Nurses, doctors, and patients are one unit that needs each other inseparably. Without nurses, doctors will be more difficult in handling patients. Without nurses, patient welfare is also neglected because nurses are health workers who foster the first and longest relationship with patients, remembering nursing services take place continuously for 24 hours a day because nurses are required to be professional, must be qualified and caring for patients [4].

One way to evaluate the quality of nursing services performed by nurses in hospitals is to conduct a survey of patient satisfaction with nursing services. Patient satisfaction can be influenced by nurses caring behavior. Nurses have the ability to care in providing nursing care to patients in the hospital. Caring is a nurse's wholehearted concern for the patient. Concern, empathy, gentle communication and nurses' love for patients will form a therapeutic nurse-client relationship. Thus the patient feels comfortable, safe, and the stress due to the illness is reduced so that patient satisfaction can be realized, but the reality in practice is still found by nurses less caring behavior towards patients [5]. 
Caring nurses in the eyes of most people today are not well developed. This situation is caused by the professionalism values of nurses that have not been applied in nursing service activities, including caring behavior as the core of nursing. Broadly speaking, people perceive professional nurses if nurses have ethics and caring in nursing services [4].

Patient satisfaction is a very important factor for evaluating the quality of nursing services performed by nurses in hospitals. Nurse caring behavior is one that is related to nursing services, caring includes human relationships and affects the quality of service and patient satisfaction. Patient satisfaction can be assessed from several dimensions including: tangible, reliability, responsiveness, assurance and empathy [5].

Makassar survey results in the South Sulawesi region with the number of respondents was 2,300 people who live in 23 regencies throughout South Sulawesi. Each regency consisted of 100 respondents with a minimum age of 17 years, and got an answer that was not good $(30.40 \%)$ which was quite significant for questions concerning the quality of health services and nurse performance that was increasing, while $6.80 \%$ of other respondents answered very poorly. Accumulatively, the results of the survey cannot deny the high level of assessment that the quality of health services and the performance of nurses do not reflect actual expectations.

Makassar Labuang Baji Hospital is one of the referral hospitals in Makassar. This nursing service is still considered to be not optimal and has received the most complaints related to nursing services. This is based on the number of reports and complaints that enter the South Sulawesi Parlement of South Sulawesi Province. There are still complaints from patients and their families about the role of nurses that are less than optimal, services that are always late and convoluted, there are still nurses who do not have a standard attitude in serving patients, and patients feel mistreated.

Based on staffing data at Labuang Baji Makassar Hospital, there were 13 nurses who worked in Inpatient Room. The numbers of patients treated in that hospital were two rooms which were 46 people divided into 5 lung diseases and some common diseases such as surgery, internal, child, and ENT, nursing care for wedge patients there are two different treatments, and there are partial, total and minimal treatments depending on the patient's condition. But most of the fulfillments that nurses fulfill are minimal fulfillment of patient needs. Based on the survey there are some patients who say that there are nurses who pay less attention to the patient's condition such as after putting an intra-venous and patient complaints are not handled quickly.

\section{Statement of the Problem}

Based on the description in the background of the problem above, then the problem can be formulated in this study. Is there a relationship between nurses' caring behavior and the level of patient satisfaction in Hospital?

\section{Purpose of Research}

To determine the level of patient satisfaction, nursing services, and the relationship of nurses caring behavior with the level of patient satisfaction in the hospital.

\section{Study Literature}

Caring can generally be interpreted as an ability to be dedicated to others, watchful oversight, feelings of love or love. Caring is ways of a dynamic approach, where nurses work to further improve its care to clients. In nursing, caring is an important core part, especially in nursing practice. The caring action aims to provide physical care and attention to emotions while increasing the client's sense of security and safety, then caring also emphasizes the individual's self, meaning that in carrying out nursing practice, nurses always respect clients by accepting the client's strengths and weaknesses so they can provide appropriate health services to patient. (Watson 1979).

Nurse caring behavior requires an increase in nurses' knowledge about humans, aspects of growth and development, responses to a constantly changing environment, limitations and strengths and basic human needs [6].

\section{Nurse Service Aspects}

The Indonesian Ministry of Health has determined that care services are said to be of good quality if nurses provide services to patients in accordance with basic aspects of care. These basic aspects include aspects of acceptance, attention, responsibility, communication and cooperation. Next, each aspect is explained as follows:

a. Acceptance Aspect, This aspect includes nurses' attitudes that are always friendly, cheerful, always smiling, greeting all patients. Nurses need to have an interest in others, accepting patients regardless of class, rank, socioeconomic and cultural background, so that the person is intact. In order to be able to perform services according to the aspects of acceptance the nurse must have an interest in others and have insight.

b. Attention Aspect, This aspect includes nurses' attitudes in providing nursing services need to be patient, generous, in the sense of being willing to provide assistance and assistance to patients voluntarily without expecting rewards, have sensitivity and be sensitive to any changes in patients, want to understand the patient's anxiety and fears .

c. Aspects of Cooperation, this spec includes the attitude of nurses who must be able to communicate well with patients, and patients' families. The existence of communication that is 
interacting between patients with nurses, and the existence of a good relationship with the patient's family.

d. Aspects of Responsibility, this spec includes the attitude of nurses who are honest, diligent in the task, able to devote time and attention, sportsmanship in the task, consistent and appropriate in acting.

\section{Sustina (2010) mentions that there are eight aspects that needs to be considered in service, namely:}

a. Concern, how far the company pays attention to consumers' emotions or feelings.

b. Physical environment, this aspect shows the level of environmental cleanliness that will be enjoyed by consumers, when they use the product.

c. Fast response, an aspect that shows the speed of the company in responding to consumer needs.

d. Ease of transactions, how easily consumers make transactions with service providers.

e. Ease of obtaining information, how much attention is the company to present information ready to eat.

f. Ease of access, how easily consumers can access service providers when consumers need them.

g. Procedure, how well the procedure must be carried out by consumers when dealing with companies.

h. The price aspect that determines the value of service experience that is felt by consumers when interacting with the company.

\section{Based on the views of some of the experts above, it can be concluded that the quality aspects of nursing services} are:

a. Acceptance includes nurses who are always friendly, cheerful, always smiling, greeting all patients. Nurses need to have the interests of others, accept patients without differentiating groups, ranks, socioeconomic and cultural backgrounds, so that the person is intact. In order to be able to perform services according to the aspects of admission nurses must have an interest in others and have broad insight.

b. Attention, including nurses' attitudes and providing nursing services, needs to be patient, generous in the sense that they are willing to provide assistance and assistance to patients voluntarily without expecting anything in return, have sensitivity and are sensitive to any changes in patients, want to understand patient anxiety and fear.

c. Communication, including the attitude of nurses who must be able to communicate well with patients, and patients' families. There is communication that interacts between patients and nurses, and a good relationship with the patient's family.

d. Cooperation, including the attitude of nurses should be able to do the job equally well with patients and families.

e. Responsibilities, including the attitude of nurses who are honest, diligent in the task, able to devote time and attention, sportsmanship in the task, consistent and appropriate in acting. As the party that buys and consumes services, patients (Tjiptono \& Candra, 2010).

As a party that buys and consumes services, patients assess the level of quality of a hospital's services. Consequently the same service can be assessed differently by different consumers. Characteristics of good quality are available and affordable, remain reasonable and safe, satisfying quality for patients served (Sabarguna, 2009). Quality is true compliance (Proper Value). For certain service units, both from technical aspects (medical science, technology and medical or health) and interpersonal (governance procedures for patient doctors: communication, empathy and patient satisfaction) (Hidayat 2009).

Good quality is available and affordable, right needs, right resources, right professional standards, or professional ethics, reasonable and safe, satisfying quality for patients served (Sabarguna, 2010). Quality according to consumers is a service that is humane, responsive, full of empathy, friendly, and communicative [7].

Quality of service is influenced by the presence or absence of criticism and complaints from patients, social institutions or non-governmental organizations even from the government though. Quality can be realized if there has been and the end of the interaction between patients and nurses (Jonirasmanto, 2009).

According to Mirza Tawi (2009), the quality of health care workers actually shows the performance (performance) of health services known as outputs (output) which is the final result of the actions of doctors and other professionals towards patients, in the sense of changes in health status and satisfaction both positive and otherwise.

While good or bad is greatly influenced by the process (process), input (input) and the environment (environment). So it is clear that whether or not the quality of health services is strongly influenced by these elements, and to ensure the good quality of health services the three elements must be pursued in such a way as to be in line with standards or needs.

a. For input are fund and physical facilities, equipment. It is generally stated that if labor and facilities (quantity and quality) do not comply with established standards (Standard of 
personnel and facilities). And if the available funds do not meet the needs, it is difficult to expect good service quality (Bruce, 2009).

b. The environmental element, which is meant by the environmental element, is a policy, management organization. In general, it is stated that if the policies, organizations and management are not in accordance with the standards and or are not supportive, it is difficult to expect good service quality.

c. The Process Element, which is meant by the process element, is a medical or nursing medical action. In general, it is stated that if the action is not in accordance with the established standards (Standards of conduct), it is difficult to expect good service quality.

\section{Role and Function of Nurses}

The function of nurses in conducting studies on healthy and sick individuals where all activities undertaken are useful for health recovery. Based on the knowledge possessed, this activity is carried out in various ways to restore patient independence as soon as possible. Maybe in the form of a nursing process is consisting of the stages of assessment, identification of problems (nursing diagnoses) planning, implementation and evaluation. The attention of professional nurses when providing nursing services is to fulfill basic human needs.

Profile of professional nurses is a description and overall appearance of nurses in carrying out nursing activities in accordance with the code of ethics. Nursing activities include the roles and functions of nursing care providers, nursing practices, nursing institution managers, client education and research activities in the field of nursing [8].

\section{The Role of Implementing Nurses}

The Role of Nurses, nurses in the Intensive Room According to the Ministry of Health (2011):

a. Manage comprehensive nursing services and care including assessment, nursing diagnosis, planning of nursing actions and evaluation on Intensive patients.

b. Acting as a member of the Intensive team, carrying out all treatment programs, according to the nursing plan agreed by the team.

c. Carry out patient evaluations by proposing further nursing programs for patients.

Role as Education According to the Ministry of Health (2011). As a nurse educator plays a role in educating individuals, families, groups and communities as well as health workers who are under their responsibility. This role is in the form of counseling to clients, as well as the form of knowledge dissemination to nursing students.
3. Role as a Manager according to the Ministry of Health (2011), In this case nurses have roles and responsibilities in managing nursing services and education in accordance with nursing management within the framework of the nursing paradigm. As a nurse manager is in monitoring and ensuring the quality of care or nursing services as well as organizing and controlling the nursing service system. Because nurses' understanding of knowledge is lacking so that the executing nurse manager is not maximal, the majority of positions, the scope of authority of the nurse's responsibility has almost no effect on planning and decision making.

\section{Overview of Satisfaction}

Satisfaction is a feeling of pleasure someone comes from the comparison between the pleasure of an activity and a product with expectations [7]. Another opinion from (Endang et al, 2010) that patient satisfaction is an evaluation or assessment after using a service that the service chosen at least meets or exceeds expectations.

Based on the description from several experts above, it can be concluded that patient satisfaction is the result of an assessment in the form of emotional responses (feelings of pleasure and satisfaction) to patients because of the fulfillment of hopes or desires in using and receiving nurse services.

According to Kotler, (2007) there are several types of methods in measuring customer satisfaction:

a. Complaints and Suggestions System, customer-oriented organizations (customer oriented) provide broad opportunities for customers to submit complaints and suggestions. For example by providing suggestion boxes, comment cards, and direct telephone relationships with customers.

b. Ghost Shopping, hire several people to act or act as potential buyers, then report their findings about the strengths and weaknesses of the company's and competitors' products based on their experience.

c. Customer satisfaction survey, survey research can be by post, telephone and direct interview. Respondents can also be asked to sort the various bid elements based on the importance of each element.

\section{Caring Overview}

Caring is an action taken in providing support to individuals as a whole. Actions in the form of caring should be taught to humans from birth, the period of development, the period of growth, the period of defense until death. Caring is the essence of nursing that distinguishes it from other professions and dominates and unifies nursing actions [9]. 
Caring is a behavior that underlies the attitude of nurses in providing nursing services to their patients. Behavior of nurses who are friendly, considerate, caring, provide explanations to patients and families when conducting examinations and actions, respect the patient, not in a hurry, calm, gentle, and understand the feelings of the patient and the patient's family [10].

\section{Relationship between Nurse Caring and Patient Satisfaction}

Many researchers define and describe the real form of caring nurses [9] in their research, summarize some literature about nurses caring behavior, and classify nurses caring behavior into two large groups' namely effective and instrumental behavior.

Effective caring behaviors of nurses are nurses' attitudes that reflect caring values namely human values, respect, caring, empathy, and relationships of trust and help [9]. Nursing caring behaviors that are included in effective behavior include all activities of nurses in forming relationships with quality patients that are based on a relationship of trust, sensitivity and empathy. Other activities that reflect effective behavior are providing support to patients such as patient supervision, providing comfort and respecting patient privacy [9].

Nurse caring instrumental behavior is behavior that shows nurses' skills and abilities cognitive and psychomotor [9]. Nurse activities that reflect instrumental caring behavior include physical activities or actions of nurses such as giving medicines, cleaning patients, meeting the basic needs of patients and the use of medical devices. Other behaviors that reflect the instrumental behavior of caring nurses are activities that are oriented towards cognitive abilities such as learning programs, health education and problem solving with systematic nursing care methods [9]. Types of Caring Types by [9]

a. Caring as a Process, Caring that is oriented towards the goal of helping others grow and actualize them. Caring as a process is a behavior that requires a large soul and is able to be tolerant.

b. Caring As a Normal Form (moral form) so that nurses must consist of people who are virtuous and have concern for patient satisfaction, which maintains dignity and respects patients as special human beings who have power, and not just physical, but also having a soul and needs must be an important part of caring behavior.

c. Caring as An Affect described as an emotion, and feeling of compassion, or empathy for the patient that encourages the nurse to provide nursing care for the client / patient. Thus these feelings must be present in every nurse in order to treat patients well.

\section{Methods of Study}

This type of research is quantitative using the correlational descriptive method which aims to examine the relationship of caring nurses with the level of client satisfaction in inpatient Labuang Baji Hospital Makassar. The research design used cross sectional time management. That is the measurement of the independent variable and the dependent variable at the same time [11]. This research was conducted at Labuang Baji Hospital Makassar. This research was conducted in July 2019.

Population is a generalization area that consists of objects / subjects that have certain quantities and characteristics that can be applied by researchers to be studied and then drawn conclusions (Notoatmodjo, 2010).

The populations in this study were inpatients in Labuang Baji Makassar Hospital. The number of inpatients was 46 people. The sample is part of the number and characteristics possessed by the population. If the population is large, and researchers may not study everything in the population, for example due to limited funds, manpower and time, then researchers can use samples taken from that population [12]. Labuang Baji Makassar Hospital, amounting to 41 people.

$$
\begin{gathered}
n=\frac{N}{1+\left(d^{2}\right)} \\
n=\frac{46}{1+46\left(0,05^{2}\right)} \\
n=\frac{46}{1+46(0,0025)} \\
n=\frac{46}{1,115}=41 \text { samples }
\end{gathered}
$$

So, the number of samples is 41 people

Where:

$\mathrm{N}$ : large population

$\mathrm{N}$ : The desired sample size

$\mathrm{d}$ : desired level of trust (0.05)

The technique of determining the number of samples in this study uses purposive sampling, namely the selection of respondents as samples based on certain considerations made by the researchers themselves, with the characteristics and conditions of the population that have been known previously [11]. Thus, researchers took samples from inpatients at Labuang Baji Hospital Makassar

1. Inclusion Criteria are criteria or characteristics that need to be fulfilled by each member of the population that can be taken 
as a sample [11]. The inclusion criteria in this study are as follows:

a. Inpatients $\geq 2$ days.

b. Patients can communicate well.

c. Patients are willing to be respondents.

2. Exclusion Criteria, is a criterion where the research subjects cannot represent the sample as a research sample. Exclusion criteria in this study:

a. Patients who are undergoing outpatient care.

b. Patients who cannot communicate well.

c. Patients are not willing to be respondents.

The instrument used in this study was a questionnaire sheet that was questionnaire A to determine caring nurses using the Guttmann scale. Where questionnaire A consists of 17 types of questions. The questionnaire was directly given to the respondent / sample. The intervention in this study was to look at the relationship of caring nurses with the level of patient satisfaction using a questionnaire.

\section{Method of collecting data}

In this study, data collection was obtained by way of:

1. Primary data is data obtained directly from the object under study and collected by the procedure, primary data obtained by researchers is to use a questionnaire measuring instrument made by researchers who then filled out by respondents.

2. Secondary data is data obtained from the installation related to the initial data collection at Labuang Baji Hospital Makassar.

All data gathered from the participants with inform consent which are signed by them.

\section{Data processing}

1. Editing, After the data is collected the researcher will conduct a selection that is checking each questionnaire that has been filled in regarding the correctness of the data in accordance with the variable

2. Codding, done to facilitate data processing by coding in the list of questions that have been filled in, namely every answer from the respondent

3. Scoring is the grading of data in accordance with a predetermined score based on a structured questionnaire.

4. Data tabulation is an activity to group data according to items determined by researchers to find out the percentage of the relationship between nurses caring behavior at Labuang
Baji Hospital Makassar.

5. Data entry is the activity of entering data that has been collected into a master table or computer database, then making a simple frequency distribution using contingency tables.

Data analysis was performed using univariate analysis and bivariate analysis as follows: (1) Univariate analysis, which is processing data carried out using a computerized statistical program. In this study, univariate analysis was conducted to find out the proportion of each research variable, namely the independent variable which is a characteristic of the research subjects also (2) Bivariate analysis is an analysis carried out to see the relationship between two variables including the independent variable and the dependent variable. In this study, bivariate analysis is used to determine whether there is an influence of the independent variable, the nurse's caring behavior with the dependent variable, which is patient satisfaction. Data obtained through a questionnaire were analyzed using the Fisher's Exact Test conducted in a statistical program.

\section{Result of Study}

\section{Univariate Analysis}

The study was conducted for 2 weeks, from 11 June 2019 to 25 July 2019, in Inpatient Labuang Baji Hospital Makassar. Data collection starts from working hours until it is finished.

Based on [Table 1] the distribution of respondents by age above, with the youngest age of 15 years and the oldest age of 71 years based on the average age of most users of health services in Labuang Baji Hospital Makassar between aged 15 to 30 years, namely as many as 21 respondents (51.2\%), while some the small number of health service users are aged 31-44 years as many as 4 respondents $(9.8 \%)$.

Based on [Table 2] the distribution of the characteristics of respondents according to the sex above it can be seen that the majority of service users with the most 25 respondents (61.0\%) are women while the minority of health service users are men as many as 16 respondents (39.0\%).

Based on [Table 3] the distribution of the characteristics of respondents according to the last education of the respondents above, it can be seen that the most are high school graduates that are 17 respondents (41.5\%) and the least are S1, SD and SLTA each having 1 respondent $(2.4 \%)$.

Based on the distribution of [Table 4] the data obtained above obtained 41 respondents with caring both 34 respondents (82.9\%) and caring less 7 respondents (17.1\%)

Based on the [Table 5] distribution, the table above shows that 
most (80.5\%) visitors to Labuang Baji Hospital Makassar were satisfied and a small portion (19.5\%) stated that they were less satisfied.

\section{Bivariate Analysis}

\begin{tabular}{|c|c|c|}
\hline Age & $\mathbf{n}$ & (\%) \\
\hline 15-30 years & 21 & 51.2 \\
\hline 31-44 years & 4 & 9.8 \\
\hline 45-58 years & 10 & 24.4 \\
\hline 59-70 years & 6 & 14.6 \\
\hline Total & 41 & 100 \\
\hline
\end{tabular}

Table 2: Gender Distribution of respondents by gender.

\begin{tabular}{|c|c|c|}
\hline Gender & n & (\%) \\
\hline Female & 25 & 61 \\
\hline Men & 16 & 39 \\
\hline Total & 41 & 100 \\
\hline
\end{tabular}

Table 3: Education Distribution of respondents based on education level.

\begin{tabular}{|c|c|c|}
\hline Education & $\mathbf{n}$ & (\%) \\
\hline S1 & 1 & 2.4 \\
\hline Diploma 3 & 2 & 19.9 \\
\hline SPK & 8 & 2.4 \\
\hline SLTA & 1 & 41.5 \\
\hline SMA & 17 & 17.1 \\
\hline SMK & 7 & 9.8 \\
\hline Middle School & 4 & 2.4 \\
\hline Elementary & 1 & 100 \\
\hline Total & 41 & 2.4 \\
\hline
\end{tabular}

Table 4: Caring nurse, Distribution of respondent characteristics based on Caring Nurse.

\begin{tabular}{|c|c|c|}
\hline Caring Nurses & n & (\%) \\
\hline Good & 34 & 82.9 \\
\hline Less & 7 & 17.1 \\
\hline Total & 41 & 100 \\
\hline
\end{tabular}

Table 5: Patient Satisfaction Distribution of respondent characteristics based on Satisfaction.

\begin{tabular}{|c|c|c|}
\hline Patient Satisfaction & n & (\%) \\
\hline Satisfied & 33 & 80.5 \\
\hline unsatisfied & 8 & 19.5 \\
\hline Total & 41 & 100 \\
\hline
\end{tabular}

Table 6: Analysis of the relationship of nurses caring behavior with the level of patient satisfaction Labuang Baji Makassar Hospital. Distribution of Nurse Caring Behavior Relationships with the Level of Patient Satisfaction.

\begin{tabular}{|c|c|c|c|c|c|c|c|}
\hline \multirow{3}{*}{ Caring Nurse } & \multicolumn{4}{|c|}{ Patient Satisfaction } & \multicolumn{2}{|c|}{ Total } & \multirow[t]{3}{*}{ P. } \\
\hline & \multicolumn{2}{|c|}{ Satisfied } & \multicolumn{2}{|c|}{ Less } & \multirow[t]{2}{*}{$\mathrm{n}$} & \multirow[t]{2}{*}{$\%$} & \\
\hline & $\mathrm{n}$ & $\%$ & $\mathrm{n}$ & $\%$ & & & \\
\hline Well & 30 & 73.27 .3 & 4 & 9.8 & 34 & 82.9 & 0.018 \\
\hline Less & 3 & & 4 & 9.8 & 7 & 17.1 & \\
\hline Total & 33 & 80.5 & 8 & 19.6 & 62 & 100 & \\
\hline
\end{tabular}


Based on the distribution of table 5. 6 the results of the analysis of this study indicate a significant relationship between caring behavior of nurses and the level of patient satisfaction in Labuang Baji Hospital Makassar, with a P-Value of 0.018, with patient perceptions saying that nurses caring behavior during treatment in the wedge room. There is $73.2 \%$ and shows satisfaction with nursing services. Respondents who had low nurses caring behaviors perceptions and showed less satisfaction with nursing services were $7.3 \%$.

\section{Discussion of Study}

The discussion in this study is presented in the form of a narrative based on the results of the research obtained by the researcher; the explanation of the discussion is adjusted to the purpose of the study which consists of caring nurses with the level of satisfaction of inpatients in Labuang Baji Hospital Makassar. Characteristics of respondents obtained during the study and related to patient perceptions of nursing services and the level of satisfaction in nursing services, including age, gender, and education level. (Simamora, 2003).

Research conducted by (Trisnantoro, 2006) explained that is a person's needs for a health service will increase with age because the need for curative services or treatment increases with age. According to the researchers' assumptions most respondents of early adulthood have the ability to provide an objective assessment, while the patient is in the hospital. The results obtained in this study are in accordance with the opinion (Trisnantoro, 2006), the high morbidity rate for women than the morbidity rate for men causes women to need more health services, so women more often use health facilities such as hospitals.

The results of the study (Radwi, 2003) stated that the level of education influences patients' perceptions of the quality of nursing services. This opinion is supported by (Yani, 1999) [13] which states that individuals who have higher education in general has gotten a lot of information about health care, and are likely to have experience of the health services more, so they have high expectations of health services. The researchers' assumptions of length of stay affect the perception and assessment of patients towards nurses caring behavior, because individual experiences about the situation can lead to different perceptions and judgments. During the treatment the patient receives treatment and service from the nurse, so that the patient can feel and give an assessment of the service and how the nurse behaves while providing nursing care to the patient.

Several previous studies showed different results, such as a study conducted (Syria, 2010) in one hospital in the city of Jakarta found the results of $53 \%$ of respondents rate nurses caring behavior has been implemented well. The nurses 'lack of knowledge about caring behavior and the nurses' perception of the work environment that is not good is a factor that causes the implementation of caring behavior by nurses who are not subject to optimal research.

In line with the (Suryani, 2010 and Agustin, 2002) in a study in adult surgical ward in a hospital in the city of Palembang, said the results showed 51, $5 \%$ of patients [16] rate the nurses have been caring for patients. Lack of nurses' understanding is the concept of caring, professional image that is still lacking, disproportionate workload, and a lack of nurse awareness of the true role and function of the nurse profession. The researchers' assumptions see a match between the results of the researchers and the level of patient satisfaction.

Patient satisfaction is a very important factor for evaluating the quality of nursing services performed by nurses in hospitals. Patient satisfaction can be assessed from several dimensions including: tangibles, reliability, responsiveness, assurance, and empathy (Kotler, 2003).

The results of this study are supported by research (Rosmilawati, 2013) about the effect of patient satisfaction on nursing services in the inpatient general hospital in Pangkep area. The results showed there was an influence between patient satisfaction with nursing services, with the results of the statistical test $p=0.002(p<\alpha)$. Patient satisfaction can be fulfilled if the process of delivering health services to consumers is in accordance with what they expect or are perceived. Meeting the needs of patients depends on their perceptions or expectations of service providers (Rama, 2011). Researcher's assumptions on patient satisfaction depend on the services of the implementing nurse; if the patient's needs are met the patient will feel satisfied.

Chi square test results obtained from the value of $p=0.018$ smaller than the value of $\alpha=<0.05$ which means that there is a relationship between caring nurses with the level of patient satisfaction [17].

The relationship between caring nurses and patient satisfaction is a very important factor in evaluating the quality of nursing services performed by nurses in hospitals and nurses caring behavior is one aspect related to nursing services, because caring includes human relationships and influences service quality and satisfaction patient. Patient satisfaction can be assessed from several dimensions which include: tangibles, reliability, responsiveness, assurance and empathy (Kotler, 2003). This is supported by research [14] about the level of patient satisfaction in the orthopedic ward with caring nurses at the University of Malaysia hospital, found that $82.7 \%$ were satisfied with nurse services such as respecting patients, calm, gentle, caring, affection and empathy.

Research in several Indonesian hospitals related to patient satisfaction, among others [15] about the relationship between patient perceptions of the dimensions of quality of nursing services 
with satisfaction of inpatients in Muhammadiyah Temanggung [18], shows that there is a significant relationship between patient perceptions of dimensions of nursing service quality with satisfaction patient. One way to evaluate the quality of nursing services performed by nurses in hospitals is to conduct a survey of patient satisfaction with nursing services; patient satisfaction can be influenced by nurses caring behavior.

Nurses who have a concern in providing nursing care to patients in the hospital are nurses who have caring attitude. This is supported by the theory put forward (Potter et al, 2009) that caring is the nurse's wholehearted concern for the patient, caring, empathy, gentle communication and the nurse's love for the patient will form a therapeutic nurse-client relationship [19]. Thus the patient feels comfortable, safe and a sense of stress due to illness suffered so that patient satisfaction can be realized, but the reality in practice is still less nurses who behave caring for patients. This is supported by research (Husein, 2006) found that $90 \%$ of patients said they did not feel comfortable with nurses, $84 \%$ of these had negative experiences because nurses did not pay attention to patient needs, especially at night $[20,21]$.

Behavior caring for patients is the essence of nursing that can contribute positively to the satisfaction of patients receiving nursing services [22]. Researchers assume that nurses have an important role in improving the quality of service [23].

\section{Summary of Study}

From the results of the study and the description above with the title of the relationship between nurses caring behavior with the level of client's satisfaction in Labuang Baji Hospital [24,25] Makassar can be concluded as follows:

a. The level of patient satisfaction in Baji Ada II Hospital in Makassar Labuang Baji Hospital has a satisfied category of 33 respondents $(80.5 \%)$.

b. Nursing services in Baji Ada II hospital in Labung Baji Makassar have good caring as many as 41 respondents (82.9\%).

c. There was a significant association between caring nurse with patient satisfaction level hospitals Makassar Baji Labuang with value $p=0.018$ where the value of $\alpha<0.05$ which means that $\mathrm{H} 0$ is rejected.

\section{Acknowledgments}

We are grateful honor to the Ministry of Health of the Indonesian Republic to allow publishing this research in international journals

\section{Funding}

The author (s) received no financial support for the research, authorship, and / or publication of this article.

\section{Declaration of Conflicting Interests}

The authors declared no potential conflict of interest with respect to the research, authorship, and / or publication of this article.

\section{Data Availability}

No data were used to support this study.

\section{Abbreviation}

None

\section{References}

1. Fadila Nur Ratna (2016) Nurse caring relationship in nursing services with hospitalization at the Salatiga City Hospital. Bachelor Study Program in Nursing Stikes Kusuma Husada. Surakarta.

2. Mony Dewi Ningsy (2014) Relationship between nurses' attitudes and patient satisfactionn care inpatient hospital grade III at PKU Muhammadiyah Yogyakarta. Program nursing studies. Aisyiyah High School of Health Sciences. Yogyakarta.

3. Anjaryani Wike Diah (2009) Inpatient satisfaction with nursing services at the Tugurejo District Hospital Semarang. Megister study program Health promotion study human resources. Diponegoro University postgraduate program. Semarang.

4. Putra pratama banner (2011) Relationship between nurses caring behavior with satisfaction level patient hospitalization manliness Class III In PKU Muhammadiyah Hospital ward Yogyakarta. Nursing high school health sciences study program 'Aisyiyah. Yogyakarta.

5. Abdul (2012) Relationship between inpatient care quality and patient satisfaction at rose ward I RSUD DR. Muewardi Surakarta. D-IV midwifery study program faculty of medicine. Sebelas Maret University. Surakarta.

6. Yuliawati Lisna Ade (2012) An Overview of Nurse Caring Behavior Towards Patients at General Hospital Inpatient Room Dr. H. Marzoeki Mahdi Bogor.

7. Nursalam (2011) Nursing research methodology. Selemba Medika. Jakarta.

8. Agustin I (2012) Nurse caring behavior and its relationship with client satisfaction installation, Adult surgery inpatient Dr. Muhammadiah Husein Palembang year 2012

9. Wulandari Rini (2015) Relationship between Nurse Caring Attitudes Towards Oral Implementatio Hygienein Intensive Room Dr. Moewardi Hospital Surakart.

10. Furqoni Dian Prima (2014) Relationship between Nurse Caring Behavior and Satisfaction Family of mental patients in IRJ Lampung Province.

11. Notoatmodjo \& Soedikjo (2010) Health research methodology. Renika copyrighted. Jakarta.

12. Sugiono (2014) R\&D quantitative research methods. Bandung, Alfabeta.

13. Agustin I (2002) Thesis: Caring Caring Behavior and its relationship to satisfaction client at Adult Surgical Inpatient Hospital Dr. Muhammad Hoesin Palembang in 2002. FIK UI post graduate program.

14. Shirley Teng KY \& Norazliah (2012) Surgical Patients, Satisfaction of Nursing Care At The Orthopedic Wards in hospital Universiti Sains Malaysia, Health Enviroment Journal 3(1): 36-43.

15. Mostopha (2008) The relationship between patient perceptions of service quality dimensions nursing with patient satisfaction. Journal of Nursing 1(2): 33-37. 
16. Christopher, KathrynHegedus (2010) Oncology patients'and Oncology nurses' perception of nurse caring behavior. European Journal of Nursing Nursing 4 (4): 196-204.

17. Kotler P (2007) Fundamentals of Marketing, Vol sideline. Index. Jakarta.

18. Kotler P (2008) Marketing Management: Analysis, Planning Implementation and Control. Prentice Hall, New Jersey.

19. Kumalasari Novita (2012) Relationship between inpatient service quality and satisfaction patient in rose ward 1 RSUD DR. Muewardi Surakarta. D-IV study program Midwifery Faculty of Medicine-Sebelas Maret University. Surakarta.
20.Sudarta Wayan I (2015) Relationship of Model Theory in Nursing Service.

21. Sustina (2010) Consumer Behavior and Marketing Communication. Bandung, Andi.

22. Simamora, Roymond (2009) Documentation of the nursing process Jember University Press, Indonesia.

23. Watson (2010) Human caring science Jon es \& Bartlett Publis hers.

24. Watson, Jean (2004) Theory of human caring.

25. Watson, Jones \& Bartlett Publishers caring human being hers; 2010. 